\title{
Continuous venovenous hemodialysis with regional citrate anticoagulation in patients with liver failure: a prospective observational study
}

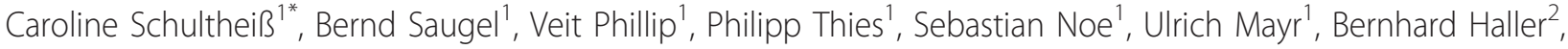
Henrik Einwächter ${ }^{1}$, Roland M Schmid ${ }^{1}$ and Wolfgang Huber ${ }^{1}$

\begin{abstract}
Introduction: Liver failure patients might be at risk for citrate accumulation during continuous venovenous hemodialysis (CWHD) with regional citrate anticoagulation. The aim of this study was to investigate the predictive capability of baseline liver function parameters regarding citrate accumulation, expressed as an increase in the calcium total/calcium ionized ( $\left.\mathrm{Ca}_{\text {tot }} / \mathrm{Ca}_{\mathrm{ion}}\right)$ ratio $\geq 2.5$, and to describe the feasibility of citrate CWHD in liver failure patients.

Methods: We conducted a prospective observational study in medical ICU patients treated in a German university hospital. We performed 43 CWHD runs using citrate for regional anticoagulation in 28 critically ill patients with decompensated liver cirrhosis or acute liver failure (maximum of two CWHD runs per patient). Liver function was characterized before CWHD using laboratory parameters, calculation of Child-Pugh and Model of End-stage Liver Disease scores, and determination of the plasma disappearance rate of indocyanine green. In addition to blood gas analysis, we measured total calcium and citrate in serum at baseline and after definitive time points for each CWHD run.

Results: Accumulation of citrate in serum correlated with an increase in the $\mathrm{Ca}_{\mathrm{tot}} / \mathrm{Ca}_{\text {ion }}$ ratio. Although the critical upper threshold of $\mathrm{Ca}_{\text {tot }} / \mathrm{Ca}_{\text {ion }}$ ratio $\geq 2.5$ was exceeded 10 times in seven different $\mathrm{CWHD}$ runs, equalization of initial metabolic acidosis was possible without major disturbances of acid-base and electrolyte status. Standard laboratory liver function parameters showed poor predictive capabilities regarding citrate accumulation in terms of an elevated $\mathrm{Ca}_{\text {tot }} / \mathrm{Ca}_{\text {ion }}$ ratio $\geq 2.5$. In contrast, serum lactate $\geq 3.4 \mathrm{mmol} / \mathrm{l}$ and prothrombin time $\leq 26 \%$ predicted an increase in the $\mathrm{Ca}_{\mathrm{tot}} / \mathrm{Ca}_{\text {ion }}$ ratio $\geq 2.5$ with high sensitivity ( $86 \%$ for both lactate and prothrombin time) and specificity (86\% for lactate, $92 \%$ for prothrombin time).

Conclusions: Despite substantial accumulation of citrate in serum, CWHD with regional citrate anticoagulation seems feasible in patients with severely impaired liver function. Citrate accumulation in serum is reflected by an increase in the $\mathrm{Ca}_{\text {tot }} / \mathrm{Ca}_{\text {ion }}$ ratio. To identify patients at risk for citrate accumulation in terms of a $\mathrm{Ca}_{\text {tot }} / \mathrm{Ca}_{\text {ion }}$ ratio $\geq 2.5$, baseline serum lactate (threshold $\geq 3.4 \mathrm{mmol} / \mathrm{l}$ ) and prothrombin time (threshold $\leq 26 \%$ ) may be useful for risk prediction in daily clinical practice. Careful monitoring of electrolytes and acid-base status is mandatory to ensure patient safety.
\end{abstract}

\section{Introduction}

Regional anticoagulation with citrate in continuous venovenous hemodialysis (CVVHD) reduces the frequency of bleeding complications, provides longer filter lifetime [1-3], and may reduce mortality in ICU patients [4].

\footnotetext{
* Correspondence: caroline.schultheiss@web.de

'II. Medizinische Klinik und Poliklinik, Klinikum rechts der Isar der Technischen Universität München, Ismaninger Straße 22, 81675 München, Germany

Full list of author information is available at the end of the article
}

Reduced risk of bleeding complications and extracorporeal clotting using citrate CVVHD might be particularly beneficial in patients with impaired coagulation due to liver failure [5]. Despite removal of up to $50 \%$ of the citrate by the dialyzer as a complex bound with ionized calcium $\left(\mathrm{Ca}_{\text {ion }}\right)$, a certain amount of citrate enters the systemic circulation. Citrate is predominantly metabolized in the hepatic citric acid cycle and clearance is almost independent of renal function and urinary

\section{Ciomed Central}


excretion [6,7]. Metabolism of citrate leads to the release of $\mathrm{Ca}_{\mathrm{ion}}$ into the systemic circulation. Citrate also contributes to the supply of alkaline plasma buffer bases, because $3 \mathrm{~g}$ bicarbonate are produced out of $1 \mathrm{~g}$ citrate $[8,9]$. In liver failure, citrate metabolism is impaired with the risk of citrate accumulation [10]. This impairment can result in a drop of $\mathrm{Ca}_{\text {ion }}$ due to complex binding between citrate and $\mathrm{Ca}_{\text {ion }}$ requiring more calcium chloride substitution at the venous line of the extracorporeal circuit. Finally, this binding leads to an increase in the concentration of total calcium $\left(\mathrm{Ca}_{\text {tot }}\right)$, defined as the sum of $\mathrm{Ca}_{\mathrm{ion}}$, protein, and citrate-bound calcium. In consequence, an increase in the $\mathrm{Ca}_{\text {tot }} / \mathrm{Ca}_{\text {ion }}$ ratio might be observed. A serum $\mathrm{Ca}_{\text {tot }} / \mathrm{Ca}_{\text {ion }}$ ratio $\geq 2.5$ is assumed to be a critical threshold for the prediction of citrate accumulation [11]. In addition, metabolic acidosis with an enlarged anion gap due to reduced citric acid cycle production of bicarbonate out of citrate and accumulation of negative loaded citrate ions might be observed as a complication of CVVHD using citrate for regional anticoagulation [12].

Considering these potential side effects, patients with overt hepatic impairment have been excluded in most of the previous studies on citrate anticoagulation. Consequently, data on the feasibility of citrate CVVHD in liver failure patients are scarce. The aim of our study was therefore to characterize predictors for citrate accumulation in terms of a $\mathrm{Ca}_{\text {tot }} / \mathrm{Ca}_{\text {ion }}$ ratio $\geq 2.5$ and to investigate the feasibility of citrate anticoagulation in patients with markedly impaired liver function. Secondary endpoints were the direct measurement of serum citrate levels and their correlation to $\mathrm{Ca}_{\text {tot }}, \mathrm{Ca}_{\text {ion }}$, the $\mathrm{Ca}_{\text {tot }} / \mathrm{Ca}_{\text {ion }}$ ratio, $\mathrm{pH}$, and anion gap as well as the evaluation of the time course of electrolytes and acid-base status during CVVHD treatment. Additionally, we analyzed the filter lifetime.

\section{Materials and methods \\ Patients}

Twenty-eight ICU patients aged 18 to 75 years suffering from decompensated liver cirrhosis (25 patients) or acute liver failure (three patients) who required renal replacement therapy due to secondary acute renal failure were included in the study. Forty-three CVVHD runs with a maximum of two runs per patient were performed in these 28 patients. Patients were consecutively enrolled between October 2009 and October 2011. The diagnosis of liver cirrhosis was confirmed either by histology and/ or by ultrasound, computed tomography or magnetic resonance tomography and typical clinical criteria such as ascites, hepatorenal syndrome or presence of esophageal varices. Presence of acute liver failure was defined as an abrupt loss of liver function without pre-existing liver disease. The patient's liver function was characterized at baseline immediately before the beginning of each CVVHD treatment by calculating the Model of End-stage
Liver Disease score [13], the Child-Pugh score [14] in case of cirrhosis, and by determining laboratory liver function parameters (aspartate aminotransferase, alanine aminotransferase, bilirubin, cholinesterase, prothrombin time). Additionally, we determined the plasma disappearance rate of indocyanine green [15]. The Simplified Acute Physiology Score II [16] and the Therapeutic Intervention Scoring System score [17] were determined in order to characterize the severity of the underlying disease. Exclusion criteria comprised severe alkalosis $(\mathrm{pH}$ $>7.55)$ or acidosis $(\mathrm{pH}<7.1)$ and deficiency of ionized calcium $\left(\mathrm{Ca}_{\text {ion }}<0.9 \mathrm{mmol} / \mathrm{l}\right)$. Two patients had to be excluded because of severe hypocalcemia, and two other patients because of severe acidosis.

This prospective observational study was approved by the institutional review board of the Technical University of Munich, Germany. Written informed consent was obtained from the patients or their legal representatives.

\section{Continuous venovenous hemodialysis treatment}

Commercially available hemodialysis devices were used for CVVHD treatment: the HF 440 (Duomedica GmBH, Maintal, Germany) for eight runs, or the Multifiltrate (Fresenius Medical Care, Bad Homburg, Germany) for 35 runs. For all CVVHD treatments, a blood flow of $100 \mathrm{ml} /$ minute and a dialysate flow of $2,000 \mathrm{ml} /$ hour were applied.

Custom-made $4 \%$ sodium citrate $(136 \mathrm{mmol} / \mathrm{l} ; 39.8 \mathrm{~g} / \mathrm{l}$ sodium citrate in 1,000 ml aqua destillata; Fresenius Medical Care) and calcium-free dialysate solution (sodium $133.0 \mathrm{mmol} / \mathrm{l}$, potassium $2.0 \mathrm{mmol} / \mathrm{l}$, calcium $0 \mathrm{mmol} / \mathrm{l}$, magnesium $0.75 \mathrm{mmol} / \mathrm{l}$, chloride $116.5 \mathrm{mmol} / \mathrm{l}$, bicarbonate $20 \mathrm{mmol} / \mathrm{l}$, glucose $1 \mathrm{~g} / \mathrm{l}$ ) were used. Calcium chloride solution was produced in the local hospital pharmacy (500 mmol/l; $73.5 \mathrm{~g}$ calcium chloride dihydrate in 1,000 $\mathrm{ml}$ aqua destillata). Sodium citrate and calcium chloride flow was started with $4 \mathrm{mmol} / \mathrm{l}$ and $1.7 \mathrm{mmol} / \mathrm{l}$ treated blood, respectively, and adapted according to the required limits of calcium between 0.25 and $0.35 \mathrm{mmol} / \mathrm{l}$ post filter and 1.12 and $1.20 \mathrm{mmol} / \mathrm{l}$ in the patient's circulation. According to the study protocol, citrate and total calcium in serum were measured at baseline just before the beginning of CVVHD treatment, after 30 minutes, as well as after 1, 4, 12, 24, and 72 hours. Blood gas analyses of the patient's circulation and $\mathrm{Ca}_{\text {ion }}$ post filter were measured at baseline, after 30 minutes, as well as after 1, 2, 4, 8, 12, 16, 20 , and 24 hours and then every 8 hours up to 72 hours of the expected CVVHD treatment time.

Citrate levels were measured enzymatically by the citrate-lyase method [18] (MVZ Labor Limbach, Heidelberg, Germany). Applying this method, citrate is metabolized to oxalacetate and acetate catalyzed by the enzyme citrate lyase. Oxalacetate is reduced to malate and lactate by the enzymes L-malate-dehydrogenase and 
L-lactate-dehydrogenase in a nicotinamide adenine nucleotide hydrogen-dependent manner. Nicotinamide adenine nucleotide hydrogen is the measured variable and is equivalent to the amount of citrate.

\section{Statistical analysis}

Quantitative data are described by the median, minimum, maximum and interquartile range (IQR), presented as the first to third quartiles, since most data are heavily skewed. For qualitative data, absolute and relative frequencies are shown. To assess the ability of baseline parameters to predict the critical event $\left(\mathrm{Ca}_{\mathrm{tot}} / \mathrm{Ca}_{\mathrm{ion}}\right.$ ratio $\geq 2.5$ during CVVHD treatment) receiver operating characteristic (ROC) analyses were performed for relevant measures. The area under the ROC curve (AUC) was estimated using the trapezoidal rule and is presented as a measure for predictive ability. For relevant baseline parameters, a 95\% confidence interval for the AUC was estimated using 10,000 bootstrap samples. A cutoff value for best discrimination between patients of high and low risk for development of citrate accumulation was assessed using the Youden Index, so from all observed values the one giving the biggest sum of sensitivity and specificity is described as the best cutoff value. For relevant baseline measures, sensitivities and specificities observed in the data for the determined cutoff values are shown. Spearman's rank correlation coefficient is presented to quantify the association between the $\mathrm{Ca}_{\text {tot }} / \mathrm{Ca}_{\text {ion }}$ ratio and citrate (serum). For all analyses, repeated CVVHD runs in the same patient were assumed to be statistically independent. All analyses were performed using the software packages SPSS version 19 (2010, SPSS Inc., Chicago, IL, USA) and R version 2.13.1 (2011; R Foundation for Statistical Computing, Auckland, New Zealand).

\section{Results}

\section{Patient characteristics}

The mean age of the 28 study patients was $57 \pm 11$ years. Eight patients were female. At baseline, 25 patients received catecholamine therapy and 24 patients were on mechanical ventilation. Three patients suffered from acute liver failure (two patients with histological proven acute alcoholic steatohepatitis, one patient with large intrahepatic hematoma). Twenty-five patients had liver cirrhosis due to alcoholism (20 patients), chronic hepatitis (one patient), alcoholism combined with chronic hepatitis (two patients), primary sclerosing cholangitis (one patient), or a cryptogenic cause (one patient). Patients were admitted to the ICU because of acute liver failure (three patients), hepatorenal syndrome (six patients), acute bleeding (five patients), hepatic encephalopathy (three patients), spontaneous bacterial peritonitis (six patients) and other infections (pneumonia in three patients, meningitis in one patient, endocarditis in one patient).

Table 1 demonstrates the baseline patient characteristics and parameters of liver function immediately before the beginning of each CVVHD treatment. Severity of hepatic dysfunction in the patients evaluated in the study is reflected by a median Model of End-stage Liver Disease score of 36 points (IQR 28 to 40), a median plasma disappearance rate for indocyanine green of $3.6 \%$ (IQR 3.2 to 5.1 ), and a median bilirubin level of $12 \mathrm{mg} / \mathrm{dl}$ (IQR 2.6 to 22.5).

\section{Acute kidney injury}

For the diagnosis of acute kidney injury (AKI), the Acute Kidney Injury Network classification was used [19]. According to this classification, two patients suffered from AKI stage I, four patients from AKI stage II and 22 patients from AKI stage III at ICU admission. Normal renal function was not present in any of the 28 study patients at the time of ICU admission. Reasons for AKI were infection/sepsis (12 patients), hepatorenal syndrome (10 patients) and bleeding shock (six patients). Confounding factors for the appearance of AKI might be the application of contrast medium (12 out of the 28 patients had a computed tomography scan with contrast medium in the last 4 weeks before the first CVVHD treatment), the transfusion intensity in the ICU (Table 2), the frequency of mechanical ventilation (when CVVHD was started: 14 cases with pressure-controlled ventilation, 25 cases with pressure-supported ventilation, four cases with spontaneous breathing) and the presence of catecholamine therapy (Table 2). The median length of ICU stay was 27 days (minimum 7 days, IQR 19 to 37 days, maximum 90 days). Twenty-four patients died in the ICU. Among the four survivors, kidney function recovered in three patients and one patient needed further hemodialysis treatment.

\section{Filter lifetime}

The aspired treatment time of 72 hours was achieved in 32 out of 43 (74\%) CVVHD running courses. No CVVHD treatment was interrupted within the first 24 hours. CVVHD runs had to be stopped prematurely because of filter clotting (two cases), a $\mathrm{Ca}_{\text {tot }} / \mathrm{Ca}_{\text {ion }}$ ratio $\geq 2.5$ (three cases), intervention/surgery (three cases), and planned stop (two cases). In one case, the reason for interruption was not documented. Two cases of premature stop due to a $\mathrm{Ca}_{\text {tot }} / \mathrm{Ca}_{\text {ion }}$ ratio $\geq 2.5$ coincided with filter clotting and surgery, respectively. Interruption of CVVHD because of an isolated elevated $\mathrm{Ca}_{\text {tot }} / \mathrm{Ca}_{\text {ion }}$ ratio $\geq 2.5$ without the opportunity to increase the calcium substitution rate of $3 \mathrm{mmol} / \mathrm{l}$ treated blood is an endpoint of clinical relevance. This endpoint was found 
Table 1 Overview of baseline liver function parameters

\begin{tabular}{lllllll}
\hline & Minimum & 25th percentile & Median & 75th percentile & Maximum & Normal range \\
\hline MELD score (points) & 19 & 28 & 36 & 40 & 40 & Maximum 40 points \\
Child-Pugh score (points) & 9 & 10 & 12 & 13 & 14 & Maximum 15 points \\
SAPS II (points) & 25 & 35 & 42 & 53 & 69 & Maximum 137 points \\
TISS score (points) & 10 & 14 & 3.6 & 5.1 & 46 & Maximum 47 points \\
ICG-PDR (\%) & 1.5 & 3.2 & 37 & 44 & 17.5 & 18 to 25 \\
Prothrombin time (\%) & 15 & 17 & 1,770 & 2,412 & 81 & 70 to 120 \\
Cholinesterase (U/l) & 584 & 1,110 & 3.2 & 3.7 & 6,417 & 5,320 to 12,920 \\
Albumin (g/dl) & 1.8 & 2.6 & 12.0 & 22.5 & 5.0 & 3.5 to 5 \\
Bilirubin (mg/dl) & 0.7 & 2.6 & 80 & 122 & 46.1 & $<1.2$ \\
ASAT (U/l) & 31 & 62 & 49 & 77 & 1859 & 10 to 50 \\
ALAT (U/l) & 13 & 30 & 2.2 & 3.4 & 598 & 10 to 35 \\
Lactate (mmol/l) & 0.7 & 1.7 & & 10.0 & $<2.4$
\end{tabular}

To characterize baseline liver function, the Model of End-stage Liver Disease (MELD) score and the plasma disappearance rate of indocyanine green (ICG-PDR) were calculated in each patient, and the Child-Pugh score only in patients with cirrhosis. The Simplified Acute Physiology Score (SAPS) and the Therapeutic Intervention Scoring System (TISS) score as well as the laboratory parameters were determined immediately before the start of each continuous venovenous hemodialysis treatment. ALAT, alanine aminotransferase; ASAT, aspartate aminotransferase.

in only one case, resulting in a treatment stop ahead of schedule.

\section{Acid-base status and electrolyte balance during CVVHD treatment}

At baseline, $\mathrm{pH}$ was in the acidotic range with values $<7.35$ in $77 \%(33 / 43)$ of CVVHD runs. During CVVHD treatment, the $\mathrm{pH}$ distribution shifted from the acidotic range towards equalized $\mathrm{pH}$ values. After 24 and 72 hours, the reference $\mathrm{pH}$ between 7.35 and 7.45 was achieved in 33\% (14/43) and 53\% (17/32) of running courses, respectively (Figure 1a). In accordance with observed $\mathrm{pH}$ values, metabolic acidosis with bicarbonate values $<22 \mathrm{mmol} / \mathrm{l}$ was observed in $65 \%(28 / 43)$ of
CVVHD treatments at baseline. After 24 hours, balanced bicarbonate levels between 22 and $26 \mathrm{mmol} / \mathrm{l}$ could be achieved in $60 \%(26 / 43)$ of CVVHD runs. However, after 72 hours of CVVHD treatment, there was a shift towards metabolic alkalosis (bicarbonate $>26 \mathrm{mmol} / \mathrm{l}$ ) in the majority $(53 \%, 17 / 32)$ of running courses. Metabolic acidosis with bicarbonate values $<22 \mathrm{mmol} / \mathrm{l}$ was obvious in only $19 \%(6 / 32)$ of CVVHD runs after 72 hours (Figure 1b). In these CVVHD runs with acidotic bicarbonate values $<22 \mathrm{mmol} / \mathrm{l}$ after 72 hours $(n=6)$, we observed a median $\mathrm{Ca}_{\text {tot }} / \mathrm{Ca}_{\text {ion }}$ ratio of 2.43 and median citrate concentration of $235 \mathrm{mg} / \mathrm{l}(1.22 \mathrm{mmol} / \mathrm{l})$. When bicarbonate levels $>22 \mathrm{mmol} / \mathrm{l}$ were observed after 72 hours of CVVHD treatment $(n=26)$, we obtained a lower median

Table 2 Context of acute kidney injury and catecholamine dosages used during continuous venovenous hemodialysis treatment

\begin{tabular}{|c|c|c|c|c|c|}
\hline & Minimum & 25th percentile & Median & 75th percentile & Maximum \\
\hline Creatinine at hospital admission (mg/dl) & 0.6 & 1.3 & 2.0 & 3.2 & 5.9 \\
\hline Urea at hospital admission (mg/dl) & 3 & 27 & 45 & 87 & 138 \\
\hline Creatinine at ICU admission (mg/dl) & 1.2 & 2.2 & 2.9 & 4.7 & 5.9 \\
\hline Urea at ICU admission (mg/dl) & 16 & 34 & 52 & 91 & 135 \\
\hline 24-hour urine production $(\mathrm{ml})$ at ICU admission & 0 & 100 & 400 & 1,000 & 2,900 \\
\hline Creatinine at first CWHD (mg/dl) & 0.8 & 2.4 & 3.4 & 5.2 & 46.0 \\
\hline Urea at first CWHD (mg/dl) & 29 & 50 & 70 & 116 & 181 \\
\hline Length of stay (days) at ICU until first CWHD & 0 & 2 & 4 & 8 & 20 \\
\hline Red blood cell units transfused before first CWHD & 0 & 0 & 2 & 4 & 14 \\
\hline Fresh frozen plasma units transfused before first CWHD & 0 & 0 & 4 & 10 & 26 \\
\hline Noradrenaline ( $\mu \mathrm{g} /$ hour) at CWHD start & 0 & 100 & 300 & 900 & 30,000 \\
\hline Noradrenaline ( $\mu \mathrm{g} / \mathrm{hour})$ at CWHD end & 0 & 0 & 300 & 900 & 30,000 \\
\hline Terlipressine ( $\mu \mathrm{g} / \mathrm{hour}$ ) at CWHD start & 0 & 0 & 0 & 80 & 240 \\
\hline Terlipressine ( $\mu \mathrm{g} / \mathrm{hour})$ at CWHD end & 0 & 0 & 0 & 40 & 240 \\
\hline
\end{tabular}

Levels of creatinine (normal range 0.7 to $1.3 \mathrm{mg} / \mathrm{dl}$ ) and urea (normal range 7 to $18 \mathrm{mg} / \mathrm{dl}$ ) are depicted at hospital admission, at ICU admission and at the beginning of the first continuous venovenous hemodialysis (CVVHD) treatment. At ICU admission all 28 study patients had impaired kidney function, meeting at least acute kidney injury stage I criteria. Median length of stay in the ICU until the first CVVHD treatment was 4 days. Catecholamine dosages are presented ( $\mu$ / hour) at the start and the ending of CVVHD treatment. At baseline, no catecholamine therapy was necessary in four out of the 43 CVVHD runs. 

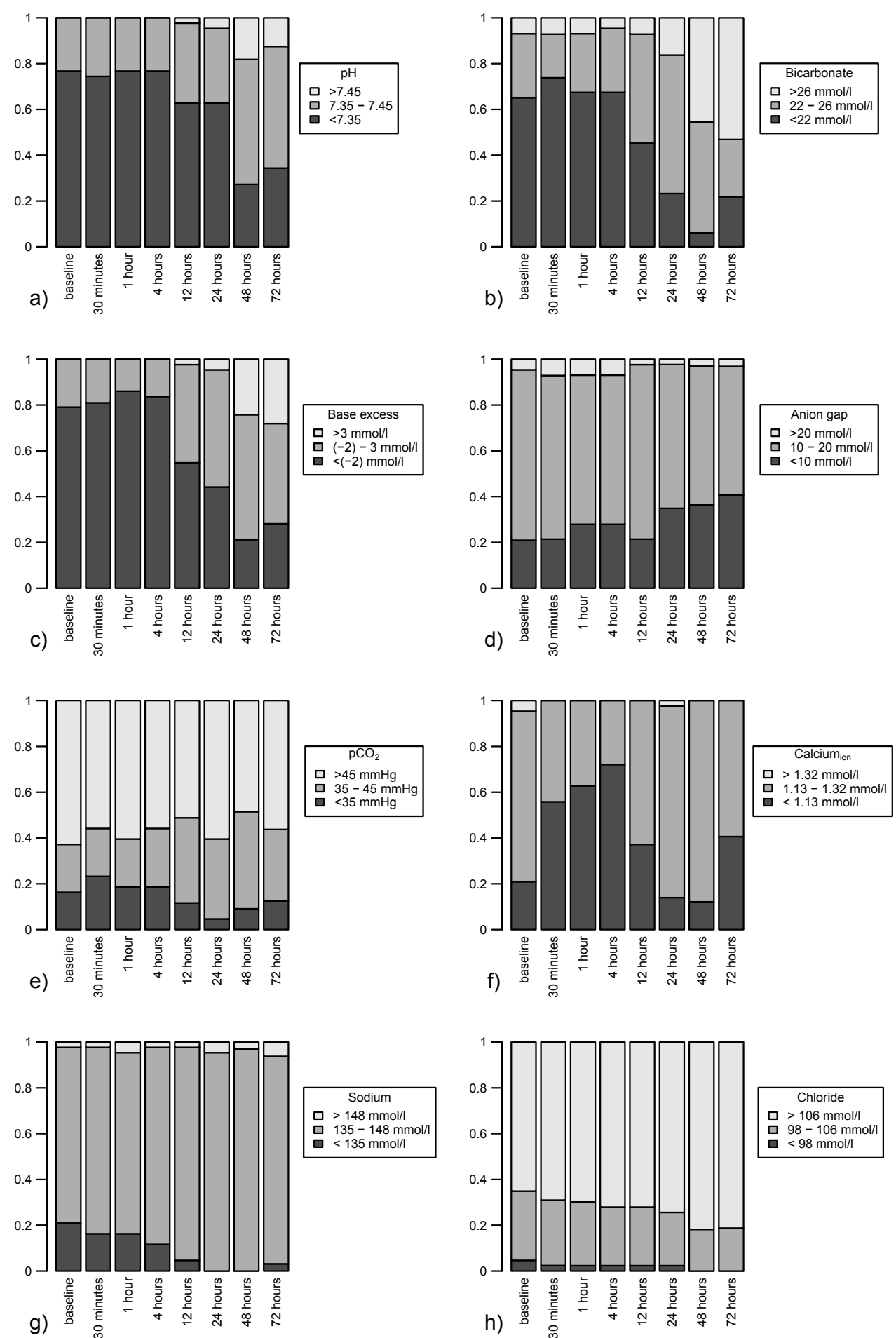

Figure 1 Acid-base status and electrolyte balance over the continuous venovenous hemodialysis treatment course. Time course of (a) pH, (b) bicarbonate, (c) base excess, (d) anion gap, (e) pCO2, (f) ionized calcium (Calciumion), (g) sodium and (h) chloride over the continuous venovenous hemodialysis (CWHD) treatment course from baseline up to 72 hours. Grey, Grey: percentage of CWHD runs achieving the reference range. White: percentage of CWHD runs above the reference range. Black: percentage of CWHD runs below the reference range. 
$\mathrm{Ca}_{\text {tot }} / \mathrm{Ca}_{\text {ion }}$ ratio of 2.15 and a lower median citrate concentration of $151 \mathrm{mg} / \mathrm{l}(0.79 \mathrm{mmol} / \mathrm{l})$.

$\mathrm{pCO}_{2}$ might also influence $\mathrm{pH}$, and the bicarbonate level but remained stable during CVVHD treatment with a trend towards hypercapnia (Figure 1e). At baseline we observed $\mathrm{pCO}_{2}$ values $>45 \mathrm{mmHg}$ in $63 \%$ of CVVHD runs (after 24 hours in 61\%, after 72 hours in 56\%). At baseline, base excess $(\mathrm{BE})$ was in the acidotic range $(<-2$ $\mathrm{mmol} / \mathrm{l})$ in $79 \%(34 / 43)$ of CVVHD treatments. During CVVHD treatment, BE normalized towards values between -2 and $3 \mathrm{mmol} / \mathrm{l}-2$ and $3 \mathrm{mmol} / \mathrm{l}$ in $51 \%$ (22/ 43) of CVVHD runs after 24 hours and in 44\% (14/32) of CVVHD runs after 72 hours. In $28 \%$ of CVVHD treatments (9/32), BE was in the alkaline range with values $\geq 3$ $\mathrm{mmol} / \mathrm{l}$ after 72 hours (Figure 1c). The anion gap was within the reference range in $74 \%(31 / 42)$ of CVVHD runs at baseline, in 63\% (27/43) after 24 hours and in $56 \%(18 / 32)$ of CVVHDs after 72 hours. In accordance with the increase of bicarbonate, there was a trend towards a decrease in the anion gap with values $<10$ $\mathrm{mmol} / \mathrm{l}$ in $41 \%(14 / 32)$ of treatments after 72 hours compared with $21 \%(9 / 42)$ at baseline (Figure 1d). The anion gap increased in only $3 \%(1 / 32)$ of citrate CVVHD treatments after 72 hours.

Regarding serum electrolytes, there was a slight trend towards hypocalcemia with $\mathrm{Ca}_{\text {ion }}$ values $<1.13 \mathrm{mmol} / \mathrm{l}$ in $41 \%(13 / 32)$ of CVVHD runs after 72 hours treatment time compared with $21 \%(9 / 43)$ at baseline. However, only mild deficiency of ionized calcium was observed with a minimum $\mathrm{Ca}_{\text {ion }}$ of $1 \mathrm{mmol} / \mathrm{l}$ after 72 hours (Table 2). The desired reference range of $\mathrm{Ca}_{\text {ion }}$ was achieved in $74 \%$ $(32 / 43)$ at baseline, in $84 \%(36 / 43)$ after 24 hours, and in $59 \%$ (19/32) after 72 hours (Figure 1f). The sodium balance was stable during CVVHD treatment, with sodium values being within the reference range of 135 to 148 $\mathrm{mmol} / \mathrm{l}$ in $91 \%$ of runs after 72 hours (Figure $1 \mathrm{~g}$ ). We observed mild hyperchloremia during CVVHD treatment (Figure 1h). Table 3 additionally demonstrates the time course of $\mathrm{pH}$, bicarbonate, $\mathrm{BE}$, anion gap, $\mathrm{pCO}_{2}, \mathrm{Ca}_{\text {ion }}$, sodium and chloride during CVVHD, including minimum and maximum values at baseline, after 24 hours and after 72 hours.

\section{Prediction of citrate accumulation in terms of $\mathrm{Ca}_{\mathrm{tot}} / \mathrm{Ca}_{\text {ion }}$ ratio $\geq 2.5$ by baseline liver function parameters}

The predictive capabilities of liver function parameters at baseline regarding a $\mathrm{Ca}_{\text {tot }} / \mathrm{Ca}_{\text {ion }}$ ratio $\geq 2.5$ were investigated using ROC analysis. For 10 out of 273 measurements determined during seven out of 43 CVVHD runs the $\mathrm{Ca}_{\text {tot }} / \mathrm{Ca}_{\text {ion }}$ ratio exceeded the critical threshold of $\geq 2.5$, suggesting citrate accumulation during CVVHD treatment after 12 hours (three runs), 24 hours (six runs) and 72 hours (one run). The highest AUC values regarding citrate accumulation were observed for serum lactate
(AUC $=0.92$; confidence interval $=0.81$ to 0.99$)$ and for prothrombin time $(\mathrm{AUC}=0.90$; confidence interval $=$ 0.70 to $>0.99$ ) (Figure 2a,b). An increase in $\mathrm{Ca}_{\text {tot }} / \mathrm{Ca}_{\text {ion }}$ ratio $\geq 2.5$ was predicted by a serum lactate level $\geq 3.4$ $\mathrm{mmol} / \mathrm{l}$ (sensitivity $86 \%$, specificity $86 \%$ ) and a prothrombin time $\leq 26 \%$ (sensitivity $86 \%$, specificity $92 \%$ ). The ROC AUC for the prediction of a $\mathrm{Ca}_{\text {tot }} / \mathrm{Ca}_{\text {ion }}$ ratio $\geq 2.5$ was 0.71 for aspartate aminotransferase, 0.49 for alanine aminotransferase, 0.67 for bilirubin, 0.73 for cholinesterase, 0.69 for the Child-Pugh score, 0.84 for the Model of End-stage Liver Disease score, and 0.54 for the plasma disappearance rate for indocyanine green.

\section{Citrate accumulation in serum}

Direct measurement of citrate demonstrated up to 29fold elevated serum citrate levels after 72 hours (median $160 \mathrm{mg} / \mathrm{l}(0.83 \mathrm{mmol} / \mathrm{l})$, IQR 113 to $215 \mathrm{mg} / \mathrm{l}(0.59$ to $1.12 \mathrm{mmol} / \mathrm{l})$, maximum $318 \mathrm{mg} / \mathrm{l}(1.66 \mathrm{mmol} / \mathrm{l})) \mathrm{com}$ pared with baseline citrate values (minimum $11 \mathrm{mg} / \mathrm{l}$ ( $0.06 \mathrm{mmol} / \mathrm{l})$, median $28 \mathrm{mg} / \mathrm{l}(0.15 \mathrm{mmol} / \mathrm{l})$, IQR 23 to $37 \mathrm{mg} / \mathrm{l}(0.12$ to $0.19 \mathrm{mmol} / \mathrm{l}))$. Citrate levels best correlated with the $\mathrm{Ca}$ tot $/ \mathrm{Ca}_{\text {ion }}$ ratio (Figure 3) but were not associated with $\mathrm{Ca}_{\text {tot }}, \mathrm{Ca}_{\text {ion }}, \mathrm{pH}$ and the anion gap over the CVVHD running time. This observation emphasizes that increases in $\mathrm{Ca}_{\text {tot }} / \mathrm{Ca}_{\text {ion }}$ ratio appropriately reflect citrate accumulation over the CVVHD treatment time.

\section{Discussion}

Despite previous studies demonstrating the feasibility of citrate anticoagulation in CVVHD, its use was usually restricted to patients without severe hepatic impairment. In case of severe liver failure, citrate can accumulate due to impaired citrate metabolism in the citric acid cycle in the liver [10,20-22]. Development of metabolic acidosis and an increased anion gap might therefore be expected. In contrast, in our study a trend to metabolic alkalosis was obvious with bicarbonate values $>26 \mathrm{mmol} / \mathrm{l}$ in $53 \%$ of CVVHD runs after 72 hours versus $7 \%$ at baseline. In parallel, BE increases over time - with $72 \%$ of running courses achieving the nonacidotic range $(>--2 \mathrm{mmol} / \mathrm{l}$ ) compared with $79 \%$ of courses being in the acidotic range $(<-2 \mathrm{mmol} / \mathrm{l})$ at baseline. Fitting to the increased bicarbonate and $\mathrm{BE}$ levels, the anion gap diminishes over treatment time. Metabolic acidosis (bicarbonate $<22$ $\mathrm{mmol} / \mathrm{l}$ ) was seen in $19 \%$ of running courses after 72 hours compared with $65 \%$ at baseline. Despite the encouraging equalization of the initial acidosis, citrate accumulation might in part be responsible for the metabolic acidosis after 72 hours because elevated citrate levels and an increased $\mathrm{Ca}_{\text {tot }} / \mathrm{Ca}_{\text {ion }}$ ratio were observed in these runs.

Altogether, in our study we observed a prevailed shift from plasma acidification towards plasma alkalization over the CVVHD treatment time. This is probably not 
Table 3 Acid-base status and electrolytes at baseline, after 24 hours and after 72 hours

\begin{tabular}{|c|c|c|c|c|c|}
\hline & Minimum & 25th percentile & Median & 75th percentile & Maximum \\
\hline pH baseline & 7.11 & 7.21 & 7.29 & 7.34 & 7.43 \\
\hline pH 24 hours & 7.21 & 7.27 & 7.33 & 7.41 & 7.51 \\
\hline pH 72 hours & 7.13 & 7.30 & 7.40 & 7.44 & 7.50 \\
\hline Bicarbonate baseline & 12.4 & 18.3 & 20.4 & 22.9 & 27.9 \\
\hline Bicarbonate 24 hours & 13.9 & 22.2 & 24.1 & 25.5 & 29.0 \\
\hline Bicarbonate 72 hours & 12.9 & 23.9 & 26.5 & 27.8 & 31.8 \\
\hline Base excess baseline & -14.2 & -7.5 & -5.0 & -3.2 & 2.5 \\
\hline Base excess 24 hours & -12.4 & -3.4 & -1.0 & 1.0 & 4.3 \\
\hline Base excess 72 hours & -17.5 & -2.2 & 1.2 & 3.5 & 7.7 \\
\hline Anion gap baseline & 6 & 10 & 13 & 15 & 28 \\
\hline Anion gap 24 hours & 3 & 9 & 11 & 15 & 24 \\
\hline Anion gap 72 hours & 4 & 9 & 11 & 13 & 28 \\
\hline $\mathrm{pCO}_{2}$ baseline & 20 & 39 & 48 & 54 & 80 \\
\hline $\mathrm{pCO}_{2} 24$ hours & 29 & 40 & 49 & 55 & 70 \\
\hline $\mathrm{pCO}_{2} 72$ hours & 30 & 43 & 46 & 55 & 86 \\
\hline $\mathrm{Ca}_{\text {ion }}$ baseline & 0.91 & 1.14 & 1.21 & 1.26 & 1.41 \\
\hline $\mathrm{Ca}_{\text {ion }} 24$ hours & 1.02 & 1.15 & 1.18 & 1.22 & 1.33 \\
\hline$C a_{\text {ion }} 72$ hours & 1.00 & 1.11 & 1.15 & 1.19 & 1.26 \\
\hline Sodium baseline & 126 & 136 & 139 & 144 & 157 \\
\hline Sodium 24 hours & 136 & 140 & 141 & 143 & 153 \\
\hline Sodium 72 hours & 133 & 142 & 143 & 145 & 151 \\
\hline Chloride 0 & 94 & 105 & 109 & 113 & 127 \\
\hline Chloride 24 hours & 97 & 106 & 108 & 111 & 120 \\
\hline Chloride 72 hours & 102 & 107 & 109 & 110 & 115 \\
\hline
\end{tabular}

Time course of $\mathrm{pH}$, bicarbonate $(\mathrm{mmol} / \mathrm{l})$, base excess $(\mathrm{mmol} / \mathrm{l})$, anion gap $(\mathrm{mmol} / \mathrm{l}), \mathrm{pCO}_{2}(\mathrm{mmHg})$, ionized calcium $\left(\mathrm{Ca}_{\text {ion }}\right.$ mmol $\left./ \mathrm{l}\right)$, sodium $(\mathrm{mmol} / \mathrm{l})$ and $\mathrm{chloride}$ $(\mathrm{mmol} / \mathrm{l})$ at baseline, after 24 hours and after 72 hours of continuous venovenous hemodialysis (CVVHD) treatment time. Forty-three CVVHD runs were included at baseline and at 24 hours, 32 CVVHD runs were included at 72 hours.

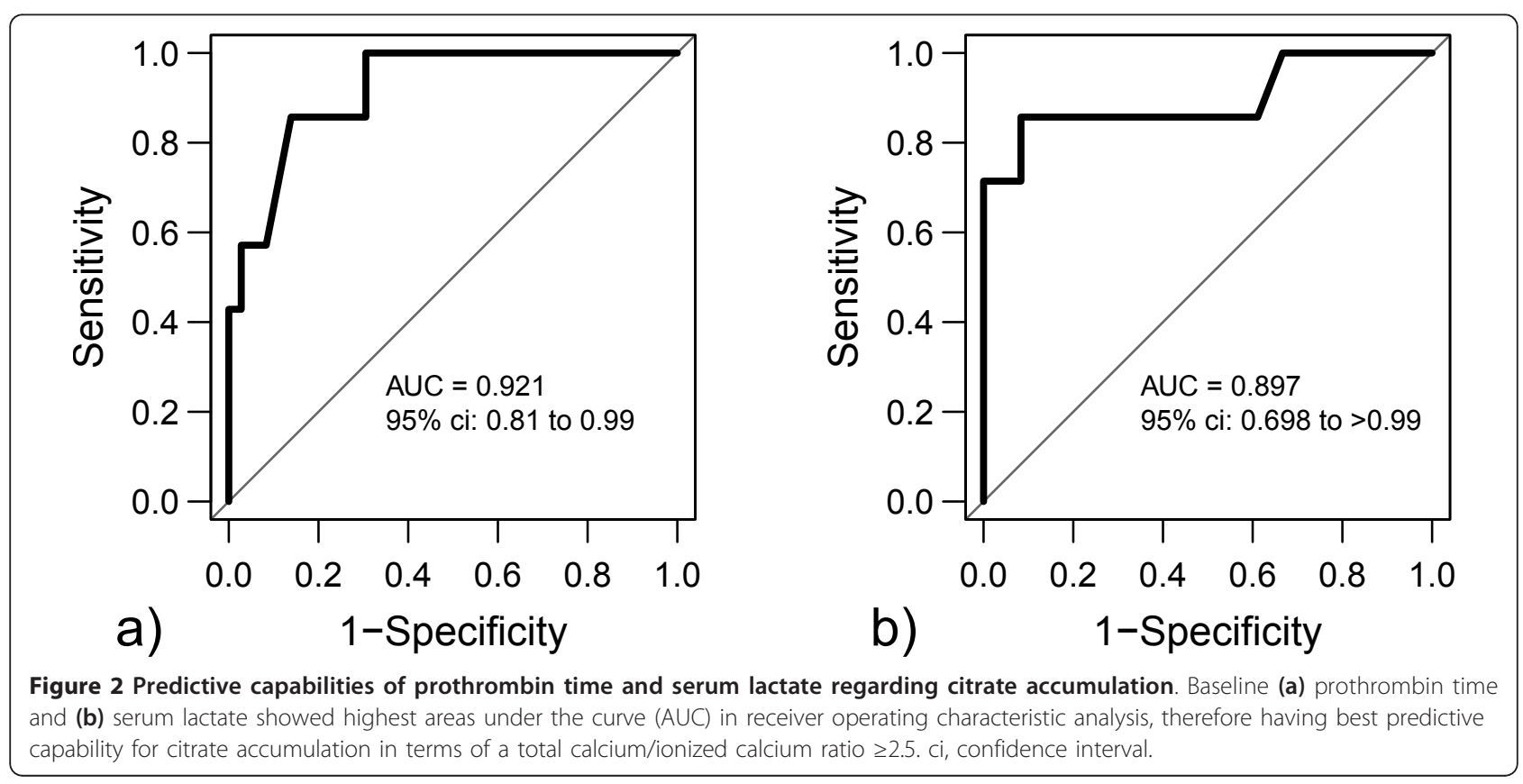




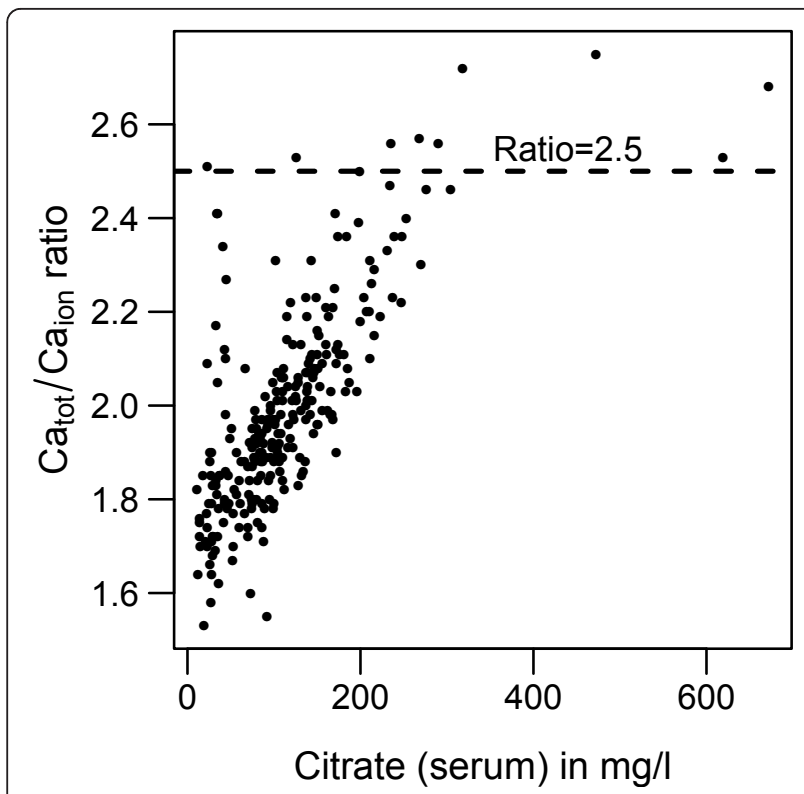

Figure 3 Correlation between citrate in serum and the total calcium/ionized calcium ratio. Citrate accumulation over continuous venovenous hemodialysis (CWHD) treatment correlates with the total calcium/ionized calcium $\left(\mathrm{Ca}_{\text {tot }} / \mathrm{Ca}_{\text {ion }}\right)$ ratio (Spearman $r=0.74)$. Of all $C W H D$ running courses, a $\mathrm{Ca}_{\mathrm{tot}} / \mathrm{Ca}_{\text {ion }}$ ratio $\geq 2.5$ was achieved 10 times.

due to a premature ending of CVVHD running courses because of a $\mathrm{Ca}_{\text {tot }} / \mathrm{Ca}_{\text {ion }}$ ratio $\geq 2.5$, as only three out of the seven CVVHD runs with an elevated ratio $\geq 2.5$ were stopped prematurely after 24 hours. All other courses with an elevated $\mathrm{Ca}_{\text {tot }} / \mathrm{Ca}_{\text {ion }}$ ratio $\geq 2.5$ achieved the expected treatment time of 72 hours. A study by Kramer and colleagues showed a reduced citrate clearance following infusion of sodium citrate and calcium chloride over 2 hours in patients with liver cirrhosis $(340 \mathrm{ml} /$ minute) in comparison with noncirrhotic patients $(710 \mathrm{ml} /$ minute $)$ [23]. Despite this proven impaired citrate clearance in liver failure patients, also in this study by Kramer and colleagues was a trend towards the development of metabolic alkalosis seen in the cirrhotic and the noncirrhotic patient groups without significant difference. Furthermore, citrate accumulation comprises the risk of hypocalcemia due to complex binding with $\mathrm{Ca}_{\text {ion }}$. In our study no severe decrease in ionized calcium was observed. This was probably prevented by regularly monitoring $\mathrm{Ca}_{\text {ion }}$ in the patient's circulation during the first few hours of CVVHD treatment in which the calcium chloride substitution at the arterial line of the extracorporeal circuit consistently needed to be elevated.

In our study, a 29-fold increase of citrate in serum was measured. This result is difficult to interpret because, to the best of our knowledge, an upper normal or even toxic level of citrate in serum is not well established. Being a physiological metabolite, citrate is probably not toxic itself but might induce metabolic disorders (especially hypocalcemia) due to complex binding between citrate and $\mathrm{Ca}_{\mathrm{ion}}$. During continuous hemofiltration, a correlation between citrate in serum and the $\mathrm{Ca}_{\text {tot }} / \mathrm{Ca}_{\text {ion }}$ ratio in critically ill patients without liver failure has previously been described by Hetzel and colleagues [24]. In our study, we demonstrate this relationship between serum citrate levels and the $\mathrm{Ca}_{\text {tot }} / \mathrm{Ca}_{\text {ion }}$ ratio in liver failure patients. The $\mathrm{Ca}_{\text {tot }} / \mathrm{Ca}_{\text {ion }}$ ratio with a critical threshold $\geq 2.5$ might therefore be a more helpful parameter to identify patients at risk for metabolic disturbances (for example, drop of ionized calcium), than the citrate level per se with a missing cutoff value indicating intoxication during citrate accumulation. Furthermore, citrate accumulation can be prevented by the application of CVVHD instead of continuous venovenous hemofiltration. CVVHD can be performed using lower blood flow while removing more citrate bound to ionized calcium over the hemodialysis filter.

One of the aims of this study was to evaluate predictive capabilities of baseline liver function parameters regarding citrate accumulation expressed as a $\mathrm{Ca}_{\text {tot }} /$ $\mathrm{Ca}_{\text {ion }}$ ratio $\geq 2.5$. We identified a prothrombin time $\leq 26 \%$ and a serum lactate level $\geq 3.4 \mathrm{mmol} / \mathrm{l}$ to be useful for predicting citrate accumulation. In certain patients, closer monitoring using blood gas analysis including $\mathrm{Ca}_{\text {ion }}$ and the plasma bicarbonate concentration might be mandatory to ensure patient safety. None of the established liver function parameters such as transaminases or bilirubin level showed appropriate predictive capabilities for citrate accumulation reflected by a $\mathrm{Ca}_{\text {tot }} /$ $\mathrm{Ca}_{\text {ion }}$ ratio $\geq 2.5$. In accordance, Kramer and colleagues could not predict citrate clearance by standard liver function tests [23]. As the citric acid cycle of the liver is oxygen dependent, lactate seems to be a very valuable predictive parameter at first sight. However, lactate elevation can be caused by hypovolemia and hypoxia due to circulatory failure but also by liver failure itself. The variety of reasons for elevated lactate levels lowers its predictive value and needs to be mentioned as a potential limitation of the present study. In addition, interference in the prothrombin time by substitutable coagulation factors is another limitation. Further limitations include the circumscribed number of patients and the observational character of this study.

\section{Conclusions}

Despite substantial accumulation of citrate in serum, we observed no major disturbances in the acid-base status during CVVHD treatment demonstrating the feasibility of citrate anticoagulation in liver failure patients. Citrate accumulation correlates with an increase in the $\mathrm{Ca}_{\text {tot }} /$ $\mathrm{Ca}_{\text {ion }}$ ratio, with a threshold $\geq 2.5$ being indicative for citrate accumulation. Patients exceeding this threshold 
might be at risk for a drop of ionized calcium and development of metabolic acidosis during CVVHD.

Whereas established liver function parameters such as transaminases and bilirubin showed poor predictive capabilities regarding prediction of a $\mathrm{Ca}_{\text {tot }} / \mathrm{Ca}_{\text {ion }}$ ratio $\geq 2.5$ in liver failure patients, a serum lactate level $\geq 3.4 \mathrm{mmol} /$ $l$ and a prothrombin time $\leq 26 \%$ where highly predictive for this endpoint. Despite interference in the prothrombin time by substitution of coagulation factors and the different reasons for lactate elevation, such as liver failure itself, these two parameters might be helpful in daily clinical practice to identify patients at risk for citrate accumulation who require close monitoring of the acidbase status and ionized calcium values during CVVHD treatment.

\section{Key messages}

- Substantial accumulation of citrate in serum of liver failure patients is observed during CVVHD treatment.

- Citrate in serum correlates with the $\mathrm{Ca}_{\text {tot }} / \mathrm{Ca}_{\text {ion }}$ ratio in liver failure patients.

- For daily clinical practice, the $\mathrm{Ca}_{\text {tot }} / \mathrm{Ca}_{\text {ion }}$ ratio might be more useful for the detection of citrate accumulation compared with citrate, because clear cutoff values for citrate in serum are missing.

- A prothrombin time $\leq 26 \%$ and serum lactate $\geq 3.4$ $\mathrm{mmol} / \mathrm{l}$ might be risk factors for citrate accumulation in liver failure patients in whom closer monitoring of the acid-base and electrolyte status is mandatory to ensure patient safety.

- CVVHD using citrate for regional anticoagulation in liver failure patients is feasible.

\section{Abbreviations}

AKI: acute kidney injury; AUC: area under the curve; BE: base excess; $\mathrm{Ca}_{\text {ion }}$ : ionized calcium; Catot: total calcium; CWHD: continuous venovenous hemodialysis; ICU: intensive care unit; IQR: interquartile range; $\mathrm{PCO}_{2}$ : partial pressure of carbon dioxide; ROC: receiver operating characteristic

\section{Acknowledgements}

The authors thank HJ Kraus from Fresenius Medical Care for technical and scientific support.

\section{Author details}

${ }^{1}$ II. Medizinische Klinik und Poliklinik, Klinikum rechts der Isar der Technischen Universität München, Ismaninger Straße 22, 81675 München, Germany. ${ }^{2}$ Institut für Medizinische Statistik und Epidemiologie, Klinikum rechts der Isar der Technischen Universität München, Ismaninger Straße 22, 81675 München, Germany.

\section{Authors' contributions}

CS, WH and RMS conceived and designed the study. BS and HE revised the manuscript for intellectual content and supported data interpretation. VP, PT, $\mathrm{SN}$ and UM contributed to conception, design and data acquisition. $\mathrm{BH}$ performed statistical analysis. All authors read and approved the final manuscript.

\section{Competing interests}

The authors declare that they have no competing interests.
Received: 1 March 2012 Revised: 29 June 2012

Accepted: 22 August 2012 Published: 22 August 2012

\section{References}

1. Morgera S: Regional anticoagulation with citrate: expanding its indications. Crit Care Med 2011, 39:399-400

2. Hetzel GR, Schmitz M, Wissing H, Ries W, Schott G, Heering PJ, Isgro F, Kribben A, Himmele R, Grabensee B, Rump LC: Regional citrate versus systemic heparin for anticoagulation in critically ill patients on continuous venovenous haemofiltration: a prospective randomized multicentre trial. Nephrol Dial Transplant 2011, 26:232-239.

3. Monchi M, Berghmans D, Ledoux D, Canivet JL, Dubois B, Damas P: Citrate vs. heparin for anticoagulation in continuous venovenous hemofiltration: a prospective randomized study. Intensive Care Med 2004, 30:260-265.

4. Oudemans-van Straaten HM, Bosman RJ, Koopmans M, van der Voort PH, Wester JP, van der Spoel JI, Dijksman LM, Zandstra DF: Citrate anticoagulation for continuous venovenous hemofiltration. Crit Care Med 2009, 37:545-552.

5. Wilkinson AH, Ash SR, Nissenson AR: Hemodiabsorption in treatment of hepatic failure. J Transp/ Coord 1998, 8:43-50.

6. Simpson DP: Citrate excretion: a window on renal metabolism. Am J Physiol 1983, 244:F223-F234.

7. Bauer E, Derfler K, Joukhadar C, Druml W: Citrate kinetics in patients receiving long-term hemodialysis therapy. Am J Kidney Dis 2005 46:903-907.

8. Mehta RL, McDonald BR, Aguilar MM, Ward DM: Regional citrate anticoagulation for continuous arteriovenous hemodialysis in critically ill patients. Kidney Int 1990, 38:976-981.

9. Díaz J, Acosta F, Parrilla P, Sansano T, Contreras RF, Bueno FS, Martínez P: Correlation among ionized calcium, citrate, and total calcium levels during hepatic tranplantation. Clin Biochem 1995, 28:315-317.

10. Apsner R, Schwarzenhofer M, Derfler K, Zauner C, Ratheiser K, Kranz A Impairment of citrate metabolism in acute hepatic failure. Wien Klin Wochenschr 1997, 109:123-127.

11. Meier-Kriesche HU, Gitomer J, Finkel K, DuBose T: Increased total to ionized calcium ratio during continuous venovenous hemodialysis with regional citrate anticoagulation. Crit Care Med 2001, 29:748-752.

12. Oudemans-van Straaten HM, Kellum JA, Bellomo R: Clinical review: Anticoagulation for continuous renal replacement therapy - heparin or citrate? Crit Care 2011, 15:202.

13. Cooper GS, Bellamy P, Dawson NV, Desbiens N, Fulkerson WJ Jr, Goldman L, Quinn LM, Speroff T, Landefeld CS: A prognostic model for patients with end-stage liver disease. Gastroenterology 1997, 113:1278-1288.

14. Pugh RN: Pugh's grading in the classification of liver decompensation. Gut 1992, 33:1583.

15. Zipprich A, Kuss O, Rogowski S, Kleber G, Lotterer E, Seufferlein T, Fleig WE, Dollinger MM: Incorporating indocyanin green clearance into the Model for End Stage Liver Disease (MELD-ICG) improves prognostic accuracy intermediate to advanced cirrhosis. Gut 2010, 59:963-968.

16. Le Gall JR, Lemeshow S, Saulnier F: A new Simplified Acute Physiology Score (SAPS II) based on a European/North American multicenter study. JAMA 1993, 270:2957-2963.

17. Cullen DJ, Civetta JM, Briggs BA, Ferrara LC: Therapeutic intervention scoring system: a method for quantitative comparison of patient care. Crit Care Med 1974, 2:57-60.

18. Zender R, de Torrenté $C$, Schneider U: [Enzymatic determination of citrate in plasma without deproteinization]. Clin Chim Acta 1969, 24:335-340.

19. Mehta RL, Kellum JA, Shah SV, Molitoris BA, Ronco C, Warnock DG, Levin A: Acute Kidney Injury Network: report of an initiative to improve outcomes in acute kidney injury. Crit Care 2007, 11:R31.

20. Meier-Kriesche HU, Finkel KW, Gitomer JJ, DuBose TD Jr: Unexpected severe hypocalcemia during continuous venovenous hemodialysis with regional citrate anticoagulation. Am J Kidney Dis 1999, 33:e8.

21. Diaz J, Acosta F, Parrilla P, Sansano T, Bento M, Cura S, Contreras RF, Belmonte JG, Bueno FS, Robles R: Citrate intoxication and blood concentration of ionized calcium in liver transplantation. Transplant Proc 1994, 26:3669-3670.

22. Marquez J, Martin D, Virji MA, Kang YG, Warty VS, Shaw B Jr, Sassano J, Waterman P, Winter PM, Pinsky MR: Cardiovascular depression secondary 
to ionic hypocalcemia during hepatic transplantation in humans. Anaesthesiology 1986, 65:457-461.

23. Kramer L, Bauer E, Joukhadar C, Strobl W, Gendo A, Madl C, Gangl A: Citrate pharmacokinetics and metabolism in cirrhotic and noncirrhotic critically ill patients. Crit Care Med 2003, 31:2450-2455.

24. Hetzel GR, Taskaya G, Sucker C, Hennersdorf M, Grabensee B, Schmitz M: Citrate plasma levels in patients under regional anticoagulation in continuous venovenous hemofiltration. Am J Kidney Dis 2006, 48:806-811.

doi:10.1186/cc11485

Cite this article as: Schultheiß et al: Continuous venovenous

hemodialysis with regional citrate anticoagulation in patients with liver

failure: a prospective observational study. Critical Care 2012 16:R162.

Submit your next manuscript to BioMed Central and take full advantage of:

- Convenient online submission

- Thorough peer review

- No space constraints or color figure charges

- Immediate publication on acceptance

- Inclusion in PubMed, CAS, Scopus and Google Scholar

- Research which is freely available for redistribution

Submit your manuscript at www.biomedcentral.com/submit 